\title{
Methodological Proposal to Develop Adaptive Thermal Comfort Studies Under Lab Controlled Conditions
}

\author{
Rincón-Martínez J. C. 1," , Fernández-Melchor F. ${ }^{1}$, Ambríz-García J. J. ${ }^{2}$, Bojórquez-Morales G. ${ }^{3}$ \\ ${ }^{1}$ Facultad de Ingeniería, Arquitectura y Diseño, Universidad Autónoma de Baja California, Ensenada, Baja California, 22860, México \\ ${ }^{2}$ División de Ciencias Básicas e Ingeniería, Universidad Autónoma Metropolitana-Iztapalapa, Ciudad de México, 09340, México \\ ${ }^{3}$ Facultad de Arquitectura y Diseño, Universidad Autónoma de Baja California, Mexicali, Baja California, 21280, México
}

Received September 29, 2020; Revised November 20, 2020; Accepted November 29, 2020

\section{Cite This Paper in the following Citation Styles}

(a): [1] Rincón-Martínez, J. C., Fernández-Melchor, F., Ambriz-García, J. J., Bojórquez-Morales, G. , "Methodological Proposal to Develop Adaptive Thermal Comfort Studies Under Lab Controlled Conditions," Civil Engineering and Architecture, Vol. 8, No. 6, pp. 1202 - 1216, 2020. DOI: 10.13189/cea.2020.080605.

(b): Rincón-Martínez, J. C., Fernández-Melchor, F., Ambríz-García, J. J., Bojórquez-Morales, G. (2020). Methodological Proposal to Develop Adaptive Thermal Comfort Studies Under Lab Controlled Conditions. Civil Engineering and Architecture, 8(6), 1202 - 1216. DOI: 10.13189/cea.2020.080605.

Copyright $\bigcirc 2020$ by authors, all rights reserved. Authors agree that this article remains permanently open access under the terms of the Creative Commons Attribution License 4.0 International License

\begin{abstract}
Thermal comfort studies developed with the adaptive approach are cross-sectional and are carried out at different periods, which make them prolonged and dependent on the current weather conditions. Meanwhile, studies under lab controlled conditions have the advantage of simulating in one single day the hygrothermal and wind conditions of a period, and manipulating them with accuracy periodically in compliance with real climatic. Thus, this paper presents a methodological proposal to develop adaptive thermal comfort studies under lab controlled conditions. The methodology is divided into three stages and fourteen activities that detail the methodological procedure to be applied before, during and after each laboratory test. It is proposed as a generic resource adaptable and reproducible to any case study, so it focuses on providing the key elements for an accurate and effective study; the particularities are defined by the objectives of each study case that adopts this methodology. The experimental procedure allows estimating the results that could be obtained from adaptive approach, since the thermal values obtained with both approaches are close to each other. Some advantages of this methodological proposal are: experimental replica; optimization of material, human, technological, temporary and economic resources; methodological reconciliation of the adaptive and predictive approaches; and the adaptive thermal comfort estimation without the influence of outside environmental.
\end{abstract}

Keywords Thermal Comfort, Controlled Environment Chamber, Adaptive Approach, Predictive Approach, Hybrid Approach, Experimental Methodology

\section{Introduction}

The thermal environment and its influence on people's health, comfort and daily performance has been studied since the 20th century [1]. While the environmental conditions of certain days stimulate the activity in people, others repress the physical and mental efforts to carry it out; in climatic zones where heat or cold conditions are excessive, the energy consumption required by biological effort is higher to achieve adaptation [2].

The interaction between the human being and his thermal environment has been studied from different disciplines: the Physiology that investigates the biological processes by which heat is produced or lost internally from the human thermoregulation mechanisms, and the Psychology that attends the psychological, emotional and affective perception of thermal environment [3].

In physiological terms, thermal comfort occurs when the human body is in energy balance with the environment [4] and it depends on the human metabolism and physiological process of thermoregulation in response to the environmental factors [5]. A psychological perspective describes thermal comfort as the "(...) condition of mind which expresses satisfaction with the thermal environment" [6], definition that implies a subjective sensation as result of thermoregulation process.

Different authors [7]-[17] have sought with their research to mediate the influence of both connotations, 
where, the basis of thermal perception focuses on the physical and psychological sensations generated by the stimuli of the thermal environment, the activity in development, the experience and the expectation of the people. Nikolopoulou [8] defines thermal comfort as "(...) psychophysiological satisfaction of the human being regarding thermal environment", where the psychological and physiological aspects of the human being intervene to perceive the thermal environment and offer a subjective vote from thermal sensation, preference, expectation, and tolerance [18]; while the ANSI/ASHRAE 55 [9] understands it as "(...) the condition of the mind (...), determined by subjective evaluations (...), which expresses satisfaction with the thermal environment".

The thermal environment analysis starts with the environment perception (psychological); subsequently, the information is analyzed and, based on it, the thermoregulation process (physiological) is activated. Then, the decision-making stage (psychophysiological) on the perceived thermal sensation continues, and finally, if it is a thermal discomfort condition, a requirement is generated to realize thermoregulation adjustments or thermal environment modifications [1],[7]-[20].

According to Humphreys and Nicol [21], thermal comfort could be studied from two approaches: the predictive and the adaptive. In the first case, the data are obtained with experimental tests under lab controlled conditions; the occupant is studied isolated from his habitat, so it is possible to influence his psychological perception and physiological functioning; and the evaluation focuses on the physiological reactions that seek an energy balance with the thermal environment. Predictive approach establishes that thermal comfort occurs when there is a balance between the human body's thermal conditions and its immediate environment; this one can be produced from the physiological processes of metabolism and thermoregulation that the human body presents against the physical conditions of the thermal environment [22]-[24]. Otherwise, the adaptive approach collects the data in field studies; the comfort temperature and the mean outdoor temperature show an associated correlation; and the evaluation focuses on the physiological and psychological reactions that influence the perception of the thermal environment. Adaptive approach warns about the actions that humans can perform to achieve thermal comfort [25], both internally (physiological and psychological processes), and externally (adaptations to their immediate environment); this adaptive approach involves quantifiable physical and biological conditions (climate, metabolism, thermal insulation), and qualifiable psychological conditions (adaptation, tolerance, experience and expectation) [26] (Figure 1). According to Humpreys and Nicol [21], human behavior is decisive for seeking and achieving thermal comfort; when a change is perceived that causes discomfort, people react instinctively and try to restore comfort conditions.

Yang et al. [27] mention that quantify variables that contribute to thermal comfort represent a challenge due to the thermal history and occupant expectations and mention that "these challenges could be solved in a laboratory study by limiting variables and focusing on one variable in each experimental case." However, some authors [28]-[30] have focused the thermal comfort evaluation in investigations that allow controlling and measuring various variables simultaneously.

Humpreys and Nicol [21] mention that laboratory studies reveal the effect that environmental conditions have on human physiology and comfort, while field studies allow to broadly identify the adaptation that humans carry out to remain in thermal comfort. However, a research study conducted by Rincón [31] has shown that the neutral temperature obtained with adaptive approach is practically equal as that obtained with predictive approach, which reveals that the evaluation environment in which the subjects are studied is not decisive; to this end, the studies were conducted simultaneously with each study approach to the same target population.

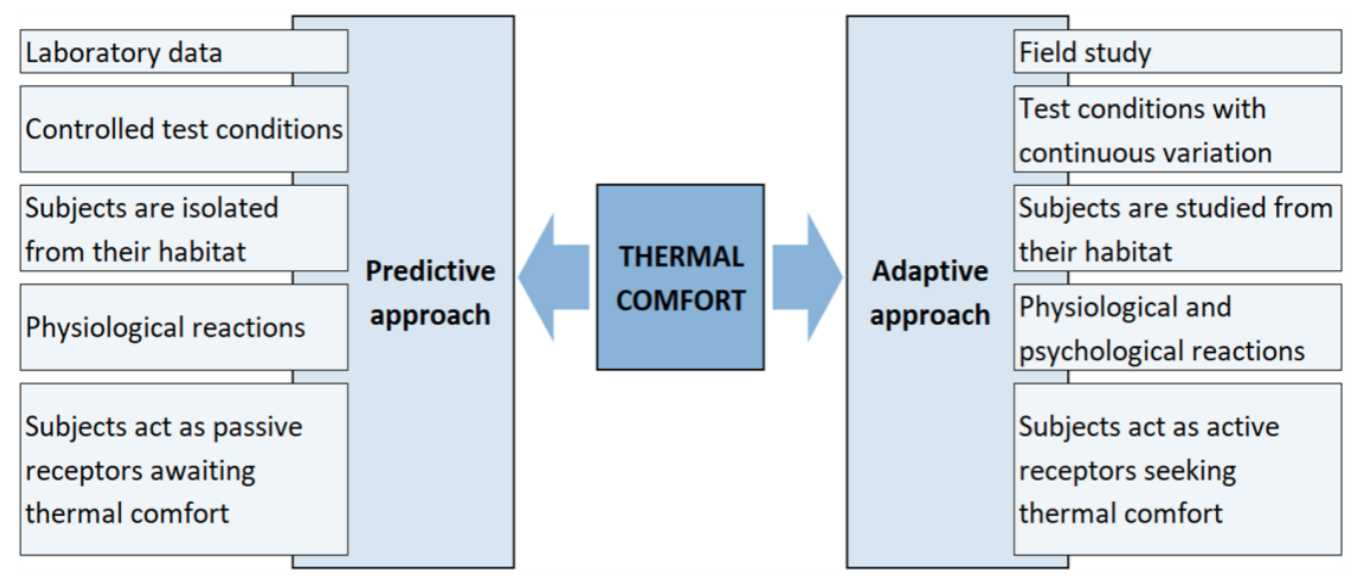

Figure 1. Differences between the predictive and adaptive approach of human thermal comfort [21] 
The difference was in the thermal comfort range, since that obtained with the field studies was more extensive than that obtained with the laboratory studies. However, if the subject is not limited in his way of acting and/or modifying his immediate environment to get thermal comfort under lab controlled conditions, the comfort range could be obtained close with both study approaches. In that context, the particularities of each study approach were developed and identified that allows reconciliation between both methodologies to prove the existence of different levels of adaptation: physiological and psychological [32].

This methodological proposal intends to make evident the possibility of estimating adaptive thermal comfort under lab controlled conditions, if during the experimental evaluations the subject is allowed a basic human adaptation (posture change, position change, intake of beverages, voluntary ventilation, modification to clothing level, etc.). Thus, it is intended to enhance the conciliation between both study approaches and identify the advantages that this could offer:

- The studies do not depend on the external hygrothermal conditions of the place where they are carried out;

- Experimental tests are developed with the normalized hygrothermal conditions of the study place;

- Annual estimation of adaptive thermal comfort in a short period of experimental tests;

- Optimization of material, human, technological and economic resources;

- The methodology can be replicated and adjusted based on the specific conditions of each study case;

- Thermal values estimated are close to those estimated in field studies.

\section{Methodological Proposal}

The methodological proposal to develop adaptive thermal comfort studies under lab controlled conditions is supported by an extensive review of literature [1],[7]-[21],[27],[33]-[35] and international standards $[6],[9],[36],[37]$ related to thermal comfort studies and the field and experimental procedures that allow data to be collected [33],[38]-[41]. Likewise, different case studies were reviewed [8],[18],[25]-[33],[35],[42], both field studies and laboratory studies, in order to identify the common practices used during each methodological procedure and develop a standardized proposal. The above, because according to the revision of thermal comfort experiments in controlled and semi-controlled environments, no standardized procedure is currently available [33].

This methodological proposal was divided into the stages shown in the Figure 2.

\subsection{General Considerations}

According to Hernández et al. [41], an experiment is a "(...) research study in which one or more independent variables (causes) are intentionally manipulated to analyze their consequences on one or more dependent variables (effects), within a control situation (...)".

Experimental studies are explanatory and correlational due to the relationships and causal effects between independent and dependent variables. The variables that have less influence on thermal perception and that could be controlled with a specific value (dependent) are such as: age, gender, residence time in the site, the last food ingested, the moods and health, the level of clothing. The independent variables are such as dry bulb temperature, radiant temperature, relative humidity, wind speed, metabolic heat and clothing insulation.

\subsection{Study Case and Target Population}

These characteristics are defined by the research scope. Study case is understood as the "(...) research holistic unit that allows responding to the problem statement, test hypotheses and develop a theory" [38].

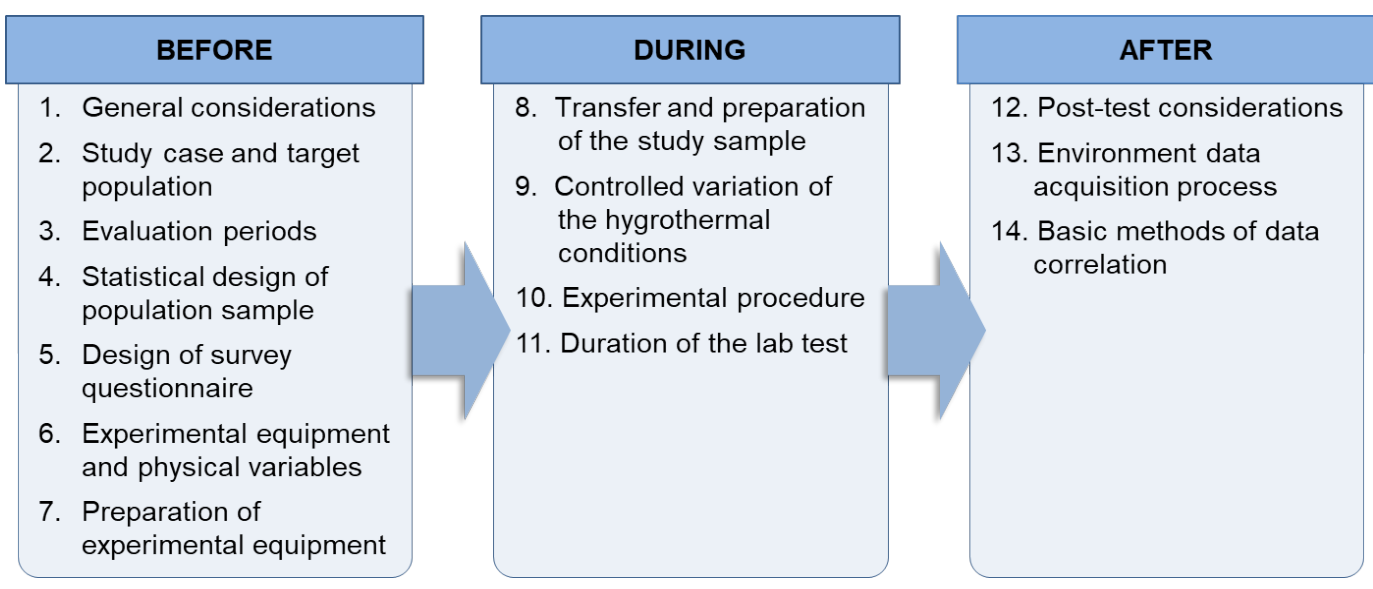

Figure 2. Stages and activities associated with the methodological proposal (Source: Own elaboration) 
For thermal comfort studies, the study case is the geographical area in which the studies are carried out, taking into account the characteristics of climate, population, evaluation spaces, activities and the customs of the study subjects, e.g., which allow limiting the study case.

Target population, also known as the study universe, is the set of cases that agree with certain specifications [41] and on which it is intended to generalize the results obtained. It can be a set of couples or families, a system (fiscal, educational, training, etc.), an organization (hospital, factory, school, etc.), a territory (community, municipality, state, nation, etc.); it consists of selecting a group of the study case with specific characteristics limited by the research objectives. For thermal comfort studies, the target population is defined by the residents of the study case who gather the criteria to achieve the research objectives; these one may be age, gender, residence time, metabolic activity, clothing, cultural or local customs, socioeconomic status, health condition, or any set of characteristics that allow defining the population group to whom the study is directed.

\subsection{Evaluation Periods and Study Periods}

Evaluation periods are those in which the experimental evaluations are carried out under lab controlled conditions, however, to define the temperature and relative humidity ranges for the evaluations, it is necessary to know the study periods that correspond to the hygrothermal conditions of a year. Study periods are determined by the monthly and annual climatic conditions, specifically, by extreme hygrothermal conditions manifested along a typical year.

For this reason, it is recommended developed thermal comfort studies based on the hygrothermal conditions of the warm period (highest monthly mean temperature), the cold period (lowest monthly mean temperature) and the thermal transition periods: one is intermediate to warm and cold periods and other is intermediate to cold and warm periods.

In order to define the four recommended study periods, a climatic characterization of the case study must be developed by the researcher with which to identify the two extreme thermal periods and the two thermal transition periods of a typical year. Subsequently, he must design the controlled environment conditions for each experimental test from the hygrothermal conditions that occur in each defined study period. Thus, the evaluation periods will be defined based on the logistics that allow the controlled environment chamber to be available; these one do not necessarily have to coincide with the study periods.

\subsection{Statistical Design of Study Sample}

Study sample is a probabilistic proportion of the target population. According to Hernández et al. [41], the sample is used to optimize time and resources. The characteristics of the study sample must be defined by the researcher according to the scope and objectives pursued with the research, in order to design a sample size representative of the target population.

These characteristics must be defined based on the variables that directly intervene in the study of the thermal comfort phenomenon in order to guarantee the internal validity of the laboratory tests. For this study, it is acceptable to use a confidence level of $95 \%$ and a confidence interval of $5 \%$, so that the study of the estimated sample allows projecting the results sought to full target population. For the sample design, it is possible to use, e.g., the Sample Size Calculator ${ }^{\circledR}$ program developed by Creative Research Systems ${ }^{\circledR}$, available online at:

http://www.surveysystem.com/sscalc.htm.

\subsection{Design of Survey Questionnaire}

Questionnaire design should be carried out in a preliminary stage to the experimental evaluation. Its adequate elaboration allows collecting accurate information that represents the sample. The questionnaire can be designed with guide from different leading authors in the investigation methodology area [41],[43],[44]. Appendix A contains an example of questionnaire; this was designed in six sections and 23 questions. Questionnaire design is a multistage process that requires:

- Information that corresponds to the research objectives.

- Type of questions and obtaining information based on facts or opinion.

- Ways to answer each question: Open or closed. Sections and questions related to thermal sensation should be based on the seven-point subjective scale suggested in ISO 7730 [6] and ANSI/ASHRAE 55 [9] (Table 1).

- Normative references and questionnaires examples. International and local standards that apply to the subject of thermal comfort must be consulted to standardize the questionnaire [6],[9],[36] as well as analogous cases in which similar questionnaires have been developed.

Table 1. Thermal sensation and preference scales used in questionnaire.

\begin{tabular}{ccc}
\hline $\begin{array}{c}\text { ISO 7730 [6] } \\
\text { ASHARAE 55 [9] }\end{array}$ & $\begin{array}{c}\text { Thermal } \\
\text { Sensation }\end{array}$ & $\begin{array}{c}\text { Thermal } \\
\text { Preference }\end{array}$ \\
\hline 3 & Hot & Much Warmer \\
2 & Warm & Warmer \\
1 & Slightly warm & Slightly warmer \\
0 & Neutral & Without change \\
-1 & Slightly cool & Slightly cooler \\
-2 & Cool & Cooler \\
-3 & Cold & Much cooler \\
\hline
\end{tabular}




\subsection{Experimental Equipment and Physical Variables}

According to Bernal [39], the experimental equipment where evaluations are carried out under lab controlled conditions is usually a controlled environment chamber (CEC), which must have monitoring, control, measurement, data acquisition and acclimatization systems.

Experimental equipment used in the experimental evaluations must monitor and record air temperature (AT), relative humidity (RH) and wind speed (WS); this must meet the technical and operational characteristics to simulate hygrothermal conditions occurring throughout the year at the place where is developed the research.

\subsection{Preparation of Experimental Equipment}

The following points present some technical conditions to be addressed before and during an experimental test in a CEC, according to Carrera y Ambríz [45]:

1. Before the start an experimental evaluation, the location and height of the seats and the measurement sensors should be customized. The sensors should be located at the point where the occupants remain most of the time [9]. An example with the location of the temperature sensors is shown in Figure 3.

According ISO 7726 [37] and ANSI/ASHRAE 55 [9], temperature sensors height must be located to $1.10 \mathrm{~m}$ from floor level for people seated (Figure 4). The seats must be located in a way that the disposition of them does not affect the hygrothermal conditions of the adjacent seat, to avoid the approach to each other influencing the response of the people evaluated. Experimental sample size depends on the surface area of the CEC $\left(2.0 \mathrm{~m}^{2} / \mathrm{subject}\right)$.

2. The CEC hygrothermal conditions must be previously customized, with the purpose of having the hygrothermal conditions required at the start of each experimental evaluation.

3. Experimental evaluation duration is an important aspect that must be determined before starting the experiment. Time depends of the periodicity of the controlled hygrothermal variations that are desired inside the chamber, as well as the stabilization (or adaptation) ranges referring to the thermal perception of the subjects. According to the experience of previous evaluations, tests duration should range between 60 and $90 \mathrm{~min}$; in the first case, for tests with children, in the second, for tests with adults.

It is recommended to develop a pilot test before formally starting with the evaluation period, to guarantee the proper functioning of CEC, measurement equipment, manage times, count on the logistics and technical stage preparations, questionnaire understanding, etc.

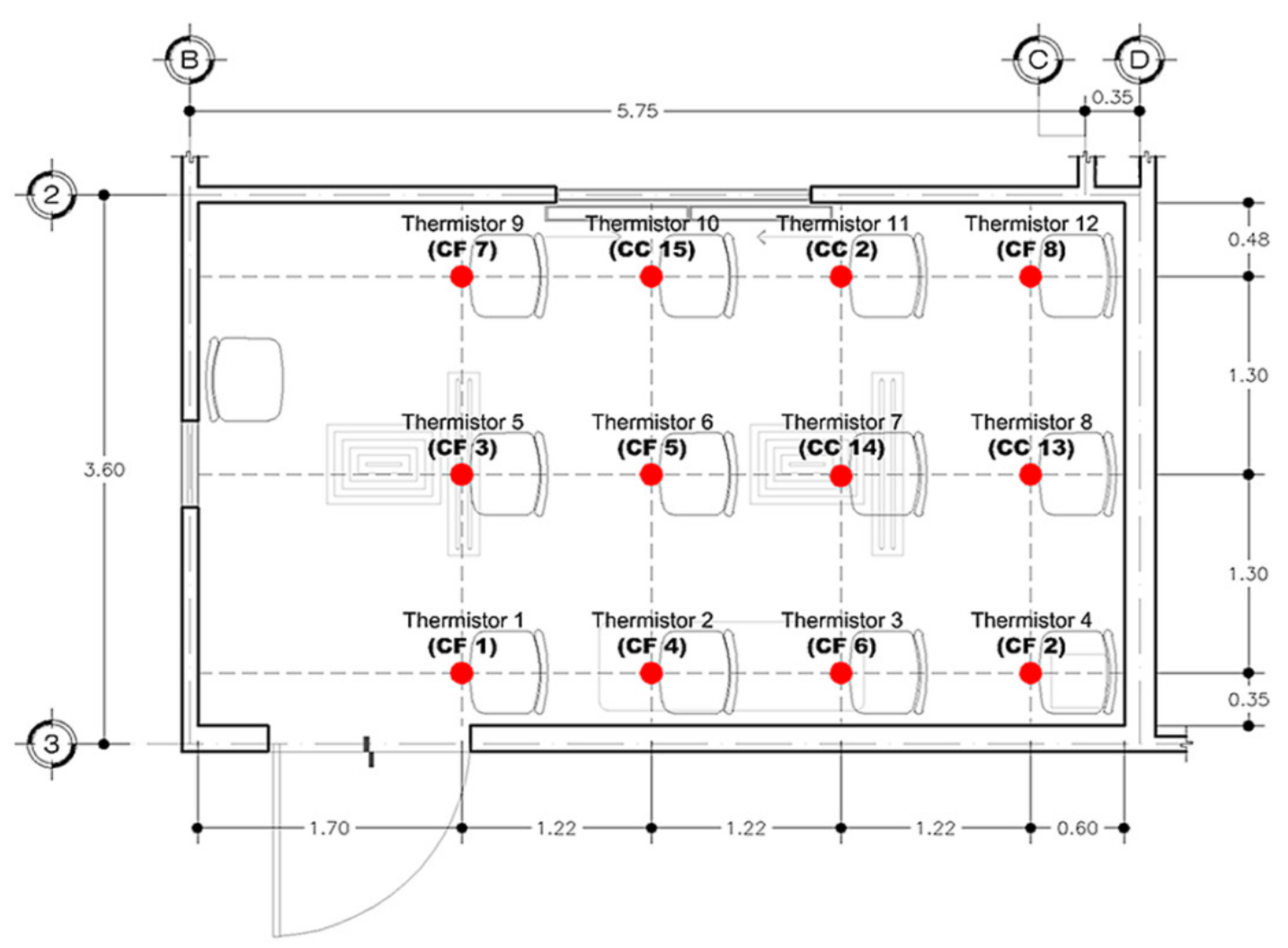

Figure 3. Temperature sensor location in CEC [31] 


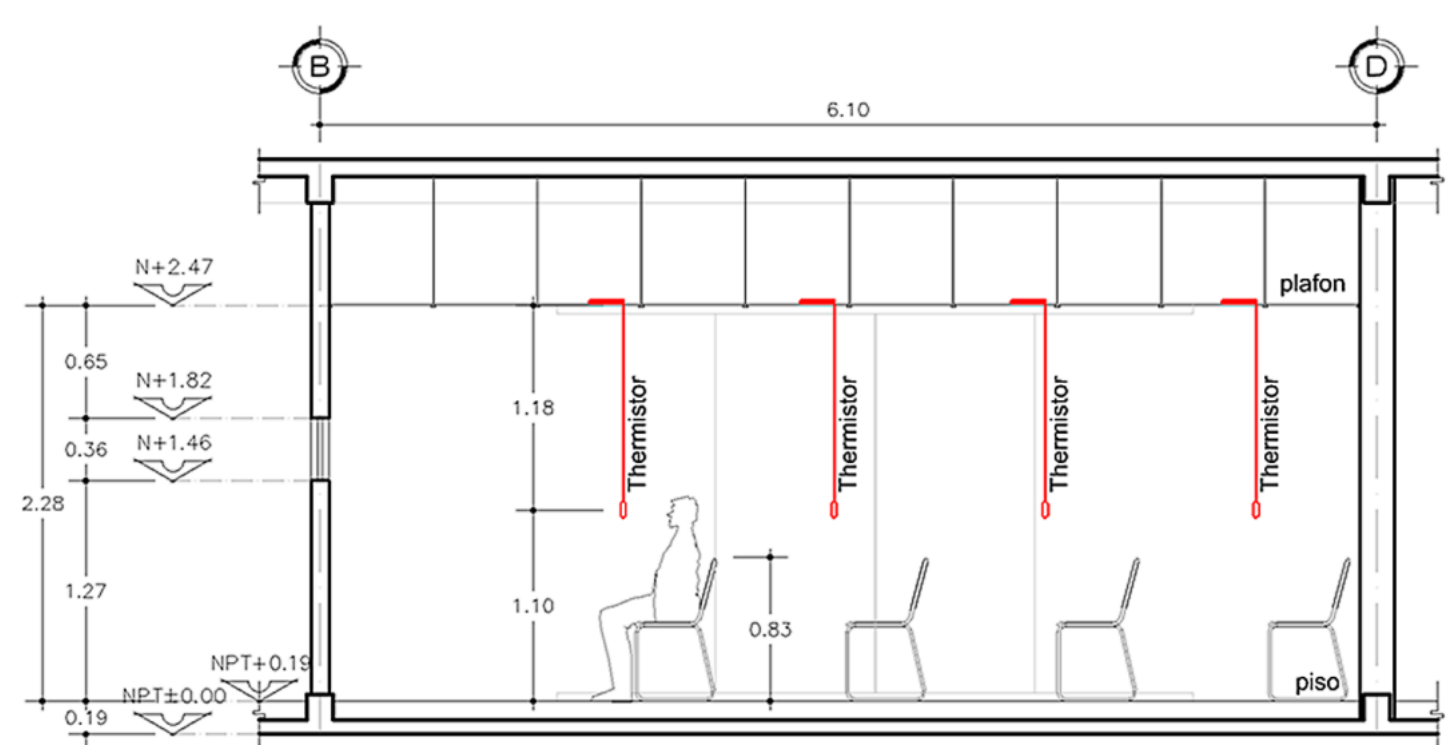

Figure 4. Temperature sensor height in relation to the floor and ceiling levels [31]

\subsection{Transfer and Preparation of the Study Sample}

If the study sample does not belong to the place where the CEC is located, some incentives must be offered to motivate the sample's participation and avoid generating a negative predisposition [41]. These stimuli could be transport, food or motivational stimuli.

People transfer is a relevant aspect that has inference in the thermal sensation; the duration of the trip should be as short as possible.

If the number of people in the vehicle is significant, it is possible that the temperature rises gradually throughout the trip, so it is advisable to record the temperature and relative humidity levels.

\subsection{Controlled Variation of the Hygrothermal Conditions}

According to Hernández et al. [41], the advantage of manipulating the independent variables of an experiment at different times, is to identify if the magnitude of the effect depends on the intensity of the stimulus. For thermal comfort studies, this premise is applied in experimental evaluations, where hygrothermal conditions are varied periodically according to the normalized ranges in real field conditions. The limits and intervals of the variations are defined from the extreme hygrothermal conditions each study period of the place where the experimental sample is located: Warm, cold and two periods of thermal transition. The intention is that the subject experiences the hygrothermal conditions of the complete year and adapts to these from position change, clothing, mechanical ventilation with hands, and intake of beverages, among others.

For this, the duration and intervals of hygrothermal variations correspond mainly to two periods:

1. Variation period. Time it would take for the CEC to modify hygrothermal conditions from one magnitude to another; e.g., going from $15{ }^{\circ} \mathrm{C}$ of AT and $95 \%$ of $\mathrm{RH}$, to $22{ }^{\circ} \mathrm{C}$ of AT and $75 \%$ of HR; this period depends of the CEC technical capacity.

2. Stabilization period. Interval in which the human body perceives a thermal change in the environment. According to ANSI/ASHRAE 55 [9] the period of cyclic fluctuation in which the subjects can perceive a significant variation in the operative temperature is $15 \mathrm{~min}$.

The intervals are the result of dividing the extreme thermal conditions of the study period by the number of possible periods of variation-stabilization. The variations of temperature, relative humidity and wind speed, must be carried out gradually, in such a way that the natural thermal perception of the participants is not disturbed. Magnitude's precision of each of the environmental variables is relevant at the start, during and at the end of the experimental evaluations, as the thermal sensation perceived of the environment will depend on each of the stabilization periods. At the beginning and end of each stabilization period, the moments of opinion (thermal comfort votes) must be recorded from questionnaires. It is recommended that the subjective scale to be used be that of seven points suggested by ISO 7730 [6] and ANSI/ASHRAE 55 [9].

The duration of experimental evaluations depends on the tolerance and relevance of the experimental sample in each study case; Hernández et al. [41] mention in this regard: The subjects maturation in an experiment is an internal invalidation source and is conceived as the participants' adverse characteristics which derive from the exposure time and may affect the experiment results (fatigue, hunger, boredom, etc.).

Figure 5 presents an example in which the variation periods, stabilization periods, hygrothermal magnitudes, 
moments of opinion and duration of the experimental evaluation in the CEC are established. This scheme can be adopted according to the conditions of each study.

Note: In Figure 5 the variations are shown in a staggered manner in order to program the variation and stabilization periods, however, in a real experimental evaluation, the hygrothermal conditions and the wind speed are presented with a short and constant variation.

These controlled conditions should only be understood as those that allow to simulate gradually the environmental conditions of the field (temperature, relative humidity and wind) - which derive, in addition, from an annual hygrothermal analysis of the place from which the study subjects come from- and not as the indiscriminate modification of these one or the strict control over the act, voluntary or involuntary, of the subject to achieve adaptation to the immediate thermal environment.

\subsection{Experimental Procedure}

Experimental procedure below described is a reference to reproduce and adapt to each study case, depending on its specific conditions. First, the experimental groups' availability and preparation, vehicular transfer, experimental equipment (CEC), support staff and questionnaires, must be guaranteed to develop the following:
1. Randomly select the subjects that will make up the experimental group based on the selection criteria for peer equivalence [41].

2. Locate to experimental group on a shaded area during $60 \mathrm{~min}$, to promote its acclimatization to the external conditions. According to Hernández et al. [41] subjects can enter the experiment evaluation with certain attitudes, expectations, and prejudices that can alter their behavior during the study. It must be analyzed which subjects can ruin the experiment and be eliminated, or, failing that, in all the groups there must be people with positive and negative attitudes since if those who have negative attitudes go to a single experimental group, the internal validity of the test will be altered.

3. Before entering the CEC, it is important to warn the study subjects that during the experimental evaluation they will be exposed to different hygrothermal conditions - similar to those of their residence city over a year- in order to promote and allow the actions relevant that may favor their human adaptation to thermal environment, such as: Bring a beverage, having different clothing levels and considering some basic physical activity, e.g. When subjects enter to CEC there is no possibility of leaving before experimental evaluation finish (it is possible that the environmental conditions change when the door is opened); in addition, change the number of subjects per experimental group puts at risk part of the internal validity of the experiment.

\section{- Preliminary activities to the experimental evaluation.}

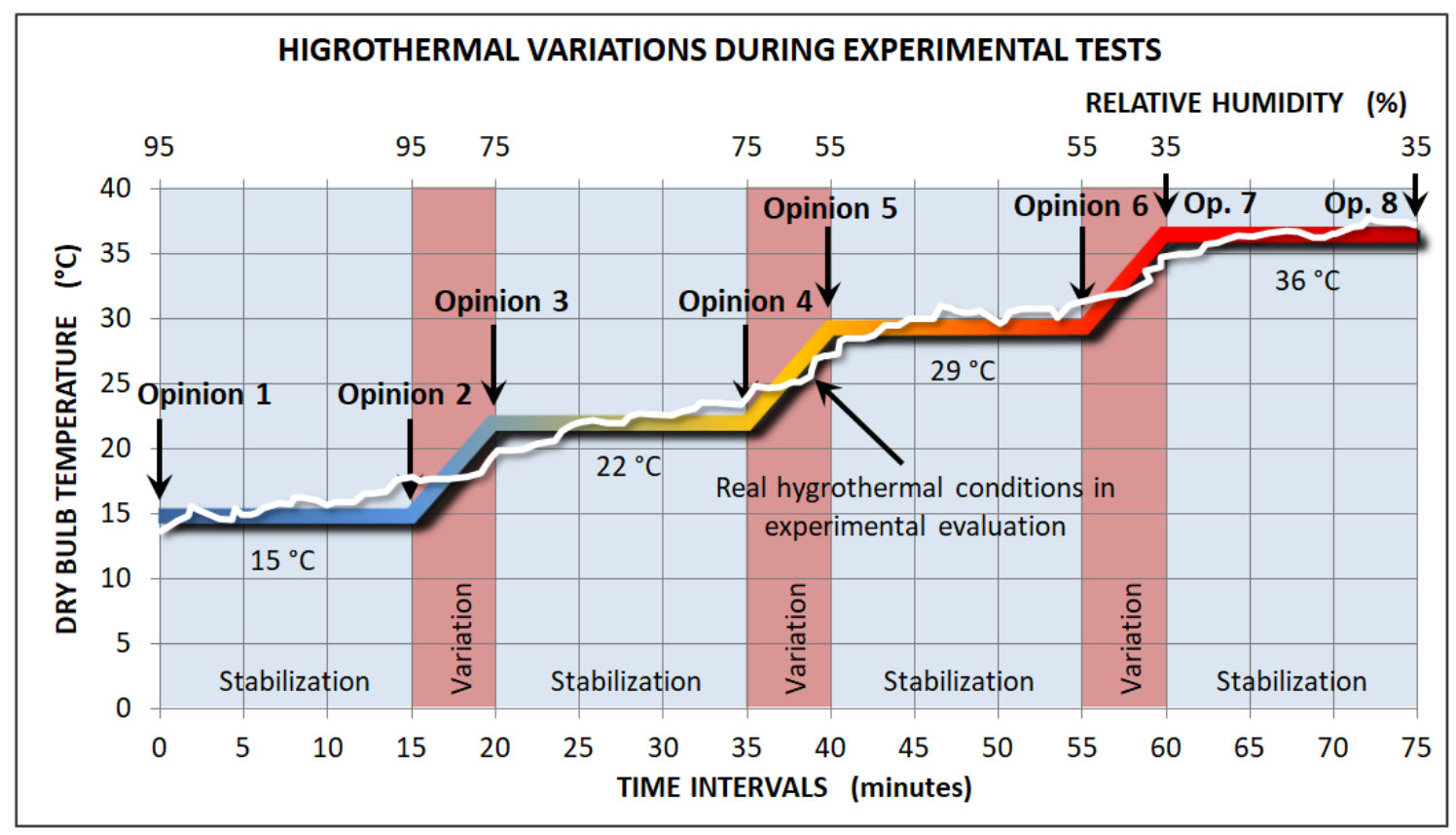

Figure 5. Hygrothermal conditions programmed for each experimental test in the CEC [31]. 
According to Hernández et al. [41] the groups must be equivalent initially and throughout the development of the experiment, except for the manipulation of the independent variable, so once the experimental test is started, it is no longer possible to leave the chamber by reasons other than forced.

\section{- Activities during the experimental evaluation.}

1. Once inside the CEC, the experimental evaluation is considered initiated and the subjects are asked to about their thermal sensation (moment one of questions 18 to 22 of the questionnaire, see Appendix A).

It is important that throughout the evaluation, the researcher avoids influencing the individual actions that each study subject can carry out to achieve and maintain thermal comfort, thereby promoting the thermal comfort range amplitude with this type of evaluation, since the subject response to the hygrothermal exposure conditions is not limited to human physiology, but is complemented by the actions that the subject takes to adapt to the thermal environment: Posture change, position change, intake of beverages, voluntary ventilation, modification to clothing level, e.g.

2. In coordination with CEC support staff, the time is taken to observe the periodicity of stabilization and/or variation of programmed hygrothermal conditions (see Controlled variation of the hygrothermal conditions).

3. The remaining questionnaire is answered as the experimental evaluation progresses and according to the moments shown in Figure 5.

Hernández et al. [41] mention that the subjects should not know the hypothesis or the experimental conditions during the evaluation, and even, they should frequently be distracted from the actual purposes of the research to avoid mechanizing the answers given with each stimulus of the independent variable.

4. When the experimental evaluation has finished, it is recommended to inform the study subjects about the evaluation and the hygrothermal conditions range to which they were exposed, as well as the contribution that their responses have in the research. Hernández et al. [41] mention that at the end of the experiment, the researcher must give a complete explanation to the study subjects of the reasons why this one was carried out.

\section{- Activities after the experimental evaluation.}

1. Support staff recovers the database of hygrothermal conditions to which each subject was exposed during the experimental evaluation for subsequent statistical processing.

\subsection{Duration of the Lab Test}

This experimental methodology suggests that each evaluation should include the duration and activities as follows:

1. $60 \mathrm{~min}$. Acclimation of study sample: "People who enter a space (...) cannot immediately find comfort conditions if they have experienced different environmental conditions just before (...). The effect of exposure or previous activity can affect the perception of comfort for about an hour" [9].

2. $75 \mathrm{~min}$. Development of the experimental test.

3. $15 \mathrm{~min}$. Acclimation after the end of the experimental test, according to ANSI/ASHRAE 55 [9].

According to Hernández et al. [41], the subjects maturation in an experiment is an internal invalidation source and is conceived as the participants' adverse characteristics which derive from the exposure time and may affect the experiment results (fatigue, hunger, boredom, etc.).

\subsection{Post-test Considerations}

The subjects that make up the experimental groups should not be repeated in another test, since exposing them to equal experimental conditions for more than once can generate internal invalidation to the laboratory test. The above, based on Hernández et al. [41], who affirm that a first experimental test can sensitize the study subjects, and when they respond to the second, their responses could be affected by this sensitization, so it would be impossible to know how much was due to the experiment and how much to such sensitization.

\subsection{Environment Data Acquisition Process}

Test coordinator requests the CEC support staff the database (in a spreadsheet to manipulate the data, to be possible) generated with the execution of experimental test, in which the monitoring and the registration of AT, RH and WV, if applicable, should be detailed, to which each study subject was exposed, in order to correlate it with the thermal sensation perceived by the subjects (collected in questionnaires) and to estimate the thermal comfort from each of the independent variables manipulated.

\subsection{Basic Methods of Data Correlation}

Data processing can be focused on the correlation of the Thermal Sensation (TS), Thermal Preference (TP) or Mood State (MS), and each of physical variables recorded during the experimental test (AT, RH, WV), from different 
correlation methods in order to identify the independent variable influence on the dependent variables, e.g.:

- Simple linear correlation.

- Simple linear correlation from means by category of thermal sensation.

- Averages by Thermal Sensation Intervals (ATSI) [42].

- ANSI/ASHRAE 55 method [9].

Due to the ATSI's [42] statistical nature of correlation and to its causal phenomenological considerations, this method is appropriate for data correlation in thermal comfort studies (Figure 6).

ATSI was developed by Gómez-Azpeitia et al. based on the Nicol [40] proposal for asymmetric climates, which consists in the use of descriptive statistics in the estimation of a neutral temperature value. ATSI estimates the temperature neutral value from the TS perceived by the study subjects - supported in the simple linear regression derived from the arithmetic means obtained from the different magnitudes of physical variables registered in each category of TS, by study period-. On the other, ATSI estimates the thermal comfort ranges -based on linear regressions derived from addition and subtraction, to the arithmetic mean, one and two times the standard deviation (SD) of the analyzed data by category of TS- that, in general, are not equidistant (asymmetric) to the neutral value. In Figure 6 is possible visualize a general diagram of the data analysis with the statistical univariate correlation method mentioned.

It is necessary to prepare the databases in advance in order to omit the atypical data that may affect the results and to provide a treatment to the comfort votes. This stage can be treated with any of the following statistical methods: Z-Score, Quartile or Weighted Hierarchy.

\section{Results and Discussion}

To validate this methodological proposal, the results obtained with an investigation [31] in which thermal comfort was estimated from the simultaneous application of the two study approaches: Adaptive and Predictive, are presented below. In each case, the methodology in which they support their theoretical bases was applied, in order to present a procedural confrontation that allowed identifying the psychophysiological responses of the subjects in each case, and to know and integrate the estimated thermal values with them. Field and experimental studies were carried out with a population sample residing in Pachuca city, Mexico (semi-cold dry bioclimate), during the extreme hygrothermal periods of a typical year: May (warm), September (wet), January (cold) and March (dry). Study subjects were young adults between 15 and 24 years old, with sedentary activity (1.0 met) [36] and a moderate clothing level $(1.0$ clo $)$ $[6],[9],[46]$.

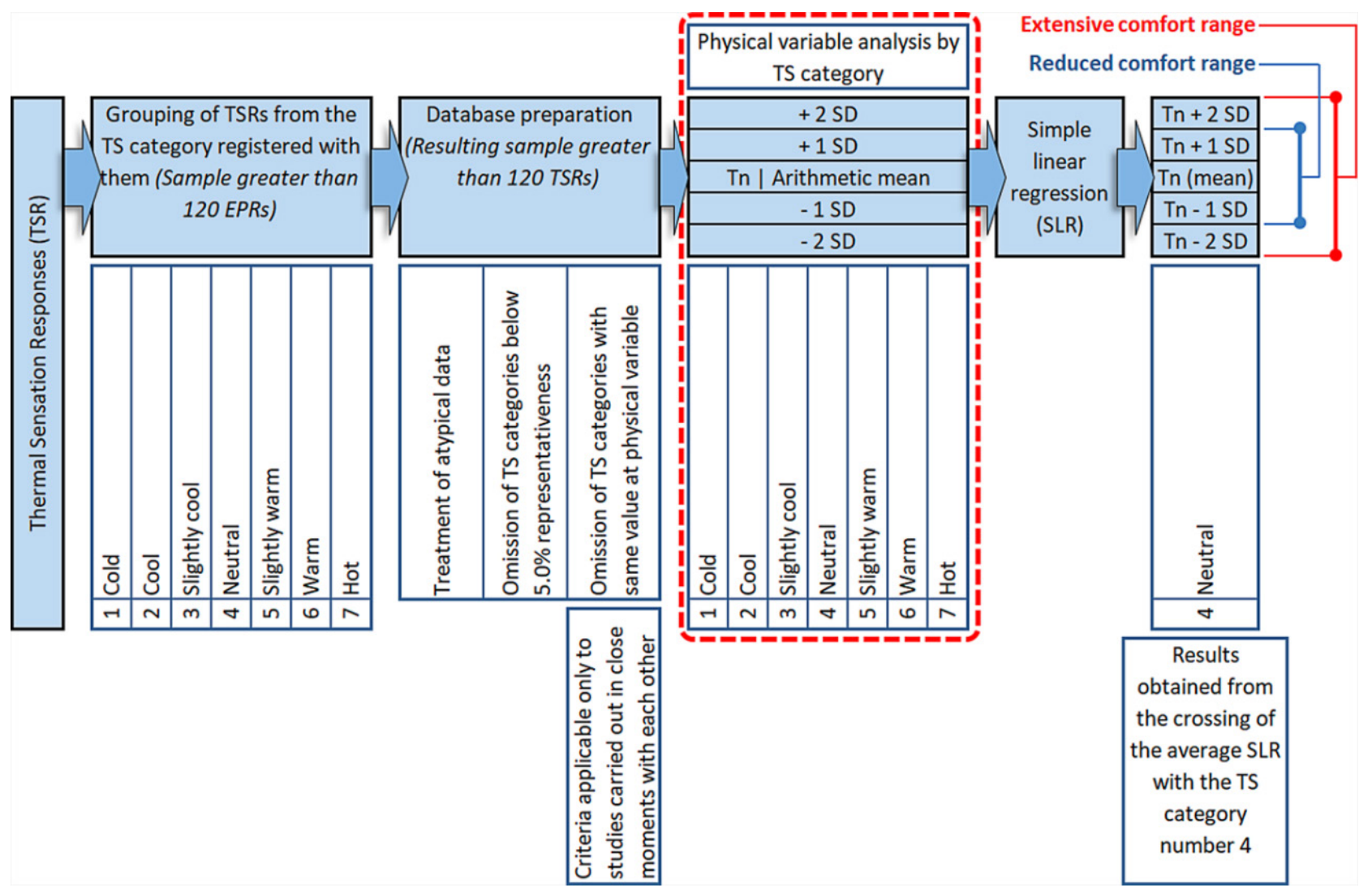

Figure 6. Diagram of data processing from the ATSI method [20]. 
During the evaluations, the physical variables recorded simultaneously to the application of the questionnaire were: AT, RH and WS [6],[9],[37]. Field studies were conducted directly in Pachuca city, while laboratory studies were carried out in a CEC located in Mexico City, $112 \mathrm{~km}$ away from the subjects' residence place [31]. Data analysis was performed with a sample of 1,556 observations for field studies and 968 observations for experimental studies; data processing was performed using the ATSI method [42], which correlated AT and TS to estimate thermal comfort for each study period.

Figure 7 shows the neutral temperature and comfort range estimated with both study approaches for each of the periods studied. Neutral values are practically equals, the difference between them is $0.2{ }^{\circ} \mathrm{C}$ in the warm and wet periods; $0.8{ }^{\circ} \mathrm{C}$, in the cold period; and, $0.3{ }^{\circ} \mathrm{C}$, in the dry period; the average difference then results in $0.4^{\circ} \mathrm{C}$, which is practically imperceptible in thermal environment context. However, the comfort ranges obtained in each case have a more pronounced difference; they oscillate between $0.3{ }^{\circ} \mathrm{C}$ and $1.3{ }^{\circ} \mathrm{C}$.

These differences are natural if one considers that during the field studies the subject was not limited to adapt to his immediate environment -through position changes, intake of beverages, opening/closing of windows and doors, modification of clothing level, passive conditioning of the environment, etc.- while in the experimental studies, each of the variables was controlled in order to know his thermal tolerance from acclimatization and physiological response (metabolism and thermoregulation mechanism) exclusively.

During the evaluations in controlled environment chamber, the methodology from predictive approach was strictly applied, so that was not only controlled by the thermal environment physical variables, but also the subjects clothing level, developed physical activity, intake of beverages, possibility of generating ventilation, subjects physical complexion, age and gender equivalence ( $50 \%$ women, $50 \%$ men), among others, to purely estimate thermal comfort from subjects physiological response. If the above variables are left to free decision and adaptation of the study subjects, and the researcher is only limited to the control of thermal environment physical variables to simulate the field environmental conditions, the possibility of achieving a thermal comfort range more extensive is opened with this evaluations type, close to those obtained with the adaptive approach.

Thermal comfort by study period and study approach

\begin{tabular}{|c|c|c|c|c|c|}
\hline \multirow[b]{2}{*}{ Approach } & \multirow[b]{2}{*}{ Thermal comfort } & \multicolumn{4}{|c|}{ Study periods } \\
\hline & & Warm & $\begin{array}{c}\text { Thermal transition } \\
\text { (Wet) }\end{array}$ & Cold & $\begin{array}{c}\text { Thermal transition } \\
\text { (Dry) }\end{array}$ \\
\hline \multirow{3}{*}{ Adaptive } & Upper limit of range & 26.9 & 25.1 & 25.4 & 26.0 \\
\hline & Neutral temperature & 23.4 & 22.2 & 21.2 & 22.3 \\
\hline & Lower limit of range & 19.1 & 20.4 & 17.3 & 18.3 \\
\hline \multirow{3}{*}{ Predictive } & Upper limit of range & 26.4 & 24.0 & 24.1 & 26.2 \\
\hline & Neutral temperature & 23.1 & 22.0 & 20.4 & 22.6 \\
\hline & Lower limit of range & 19.4 & 20.0 & 16.7 & 19.0 \\
\hline
\end{tabular}

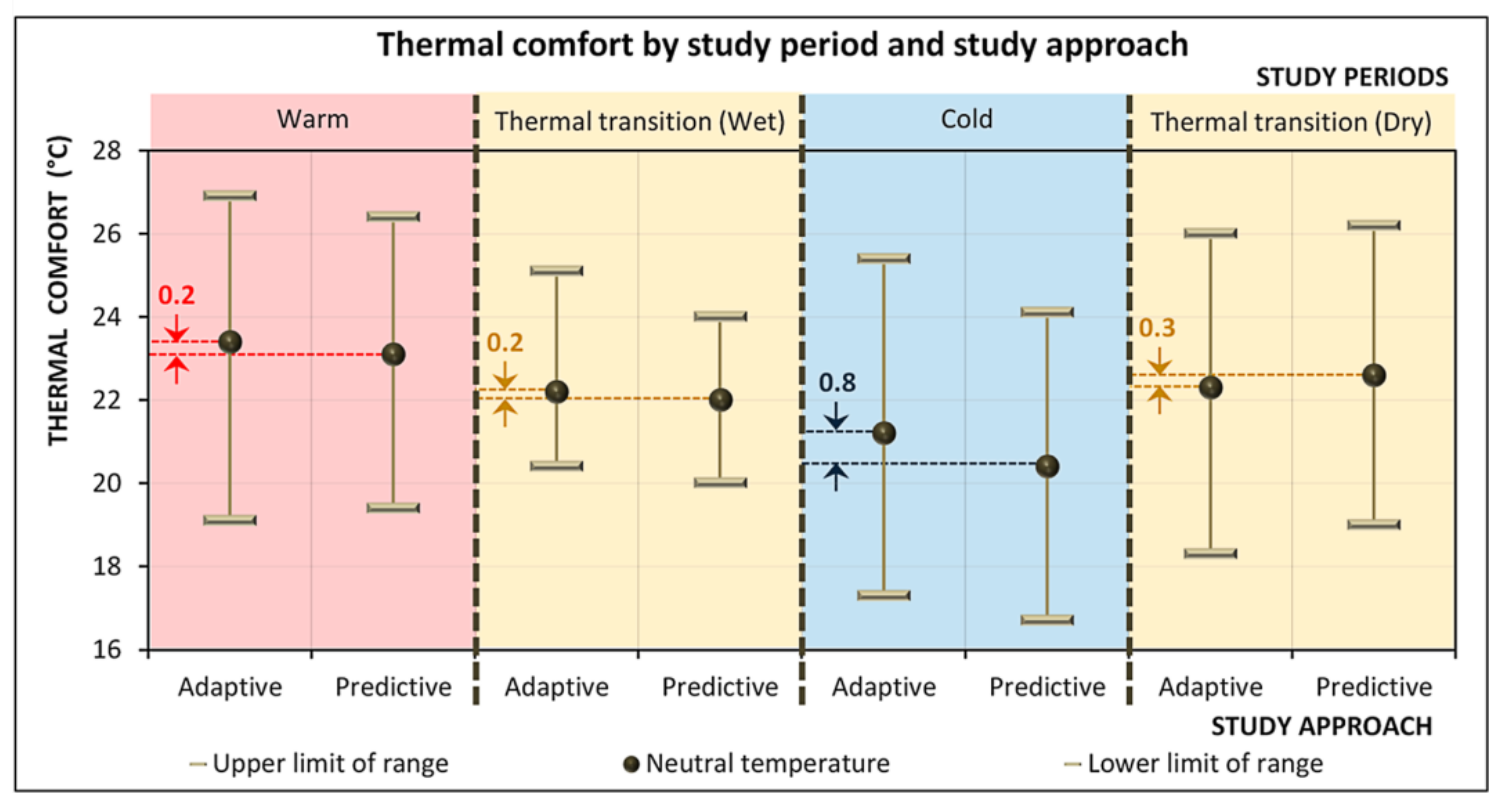

Figure 7. Thermal comfort estimated in an investigation [31] in which both study approaches were applied. 
Statistical characteristic that was allowed to establish the difference between the estimated values with each study approach was the slope of the linear regressions on which the ATSI method [42] is based to estimate thermal comfort, so that those one generated with the approach adaptive presented a lower inclination (lower slope) to that shown by those of the predictive approach - due to the greater range of hygrothermal conditions that the subjects tolerate on site derived from their free and voluntary psychophysiological adaptation-, which influenced so that thermal comfort range amplitude estimated with the adaptive approach was more extensive that the estimated with the predictive approach [31]. In the particular case of the thermal transition periods, the $\mathrm{RH}$ was the physical variable that determined the thermal comfort range amplitude, so it is possible to visualize that in the wet period, the amplitude is less than that of the dry period; this is due to the influence that RH has on the thermal sensation perceived by the subjects.

\section{Conclusions}

This methodological proposal allows reconciling the theoretical bases of adaptive and predictive approaches of thermal comfort and has the following advantages:

- Estimation of adaptive thermal comfort from lab controlled conditions;

- There is no dependence on the external hygrothermal conditions;

- It uses the normalized hygrothermal conditions of a typical period to simulate the experimental tests conditions;

- Precision in the measurements and, therefore, in the thermal comfort values estimated;

- Optimization of material, human, technological and economic resources;

- Estimation of adaptive thermal comfort of a complete year in a short period of experimental tests;

- The methodology can be replicated and adjusted based on the specific conditions of the study case carried out.

The simulated physical conditions in laboratory can correctly simulate the site environmental conditions in a typical period, and, therefore, the subject conditions of acclimatization, including the specific actions of own adaptability to achieve thermal comfort (position change, level of clothing adequacy, mechanical ventilation with hands, drink intake, etc.), however, the chamber conditions cannot get an adaptable environment (opening doors and windows, protecting yourself in the shade and manipulating curtains and mechanical conditioning equipment, among others): genuine feature of a controlled environment chamber which a sufficient degree of isolation is required to achieve the simulation of the desired environmental conditions. Therefore, this methodology allows to obtain a high certainty degree on the temperature neutral estimation of a typical period, because the results that could be obtained in field studies are close to the obtained with laboratory studies, the difference lies in the thermal comfort ranges amplitude, which could be resolved with a basic human adaptation during experimental evaluations.

In this sense, the thermal comfort estimated with the predictive approach can be homologated with that estimated with the adaptive approach, since the characteristics related to human adaptability in field studies are allowed in laboratory evaluations, such as the clothing level, metabolic activity, posture change, intake of beverages, own movements to generate ventilation, etc. Additionally, as is done with the adaptive approach, some independent variables, cataloged by Hernández et al. [41] as foreign or with little or no effect on the research objectives, they are considered and recorded in laboratory tests with the predictive approach, but discriminated during data processing in order to obtain generic models of thermal comfort applicable to most of the study population; such is the case of BMI, age, gender, skin color, residence time on site, the latest food intake, mood and health.

In summary, the tests carried out in a controlled environment chamber allow to evaluate the adaptation that is noticed with actions such as position change, ventilation generation with the hand and expectations after the test (taking a beer, for example); actions, under the scheme of control of dependent variables practiced in each of the tests carried out, were optionally chosen by the subjects. This allows to glimpse that if the study subjects enter the controlled chamber with beverages and/or additional clothing, e.g., they can take up them as thermal adaptation alternative, so that the results could be estimated more accurately from human adaptation to achieve thermal comfort in an active way, and not only passive from the thermoregulation mechanisms. This allows extended the comfort ranges magnitude. Therefore, it would be advisable to allow the experimental groups to enter the CEC with beverages and the clothing amount that they decide, in order to achieve adaptability in tests carried out under controlled laboratory conditions and thereby generate that not only the neutrality value is close to that estimated with the site studies, but also the thermal comfort ranges get closer. This methodology is visualized as an alternative to obtaining results from the adaptive approach in less time than required by field studies.

\section{Acknowledgments}

Acknowledgments are extended to the following institutions/personalities for providing the facilities and/or support to adequately carry out the research that is partially reported in this paper: 1 . Instituto Tecnológico de Pachuca (ITP), 2. Universidad Autónoma Metropolitana (UAM-Azcapotzalco), 3. People who helped with the survey. 


\section{Appendixes}

Appendix A: Questionnaire used during the experimental evaluations.

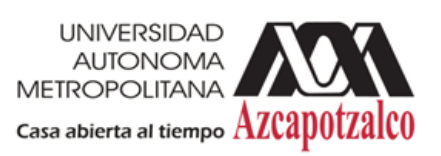

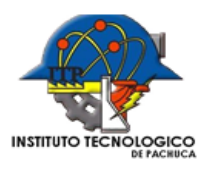

Metropolitan Autonomous University - Azcapotzalco Postgraduate in Design (CYAD)

Research line: Bioclimatic Architecture

Elaboration: M.D. Julio César Rincón Martínez

Review: Dr. Arq. Gonzálo Bojórquez Morales

\section{THERMAL COMFORT INDOORS: HIGHER EDUCATION INSTITUTION IN SEMI-COLD BIOCLIMATE}

(Study case: Pachuca de Soto, Hidalgo)

Objective: To identify the hygrothermal sensation and preference of Technological Institute of Pachuca students under lab controlled conditions in order to estimate the thermal comfort in the classroom.

*Your responses are very important for this research, please answer each question honestly.

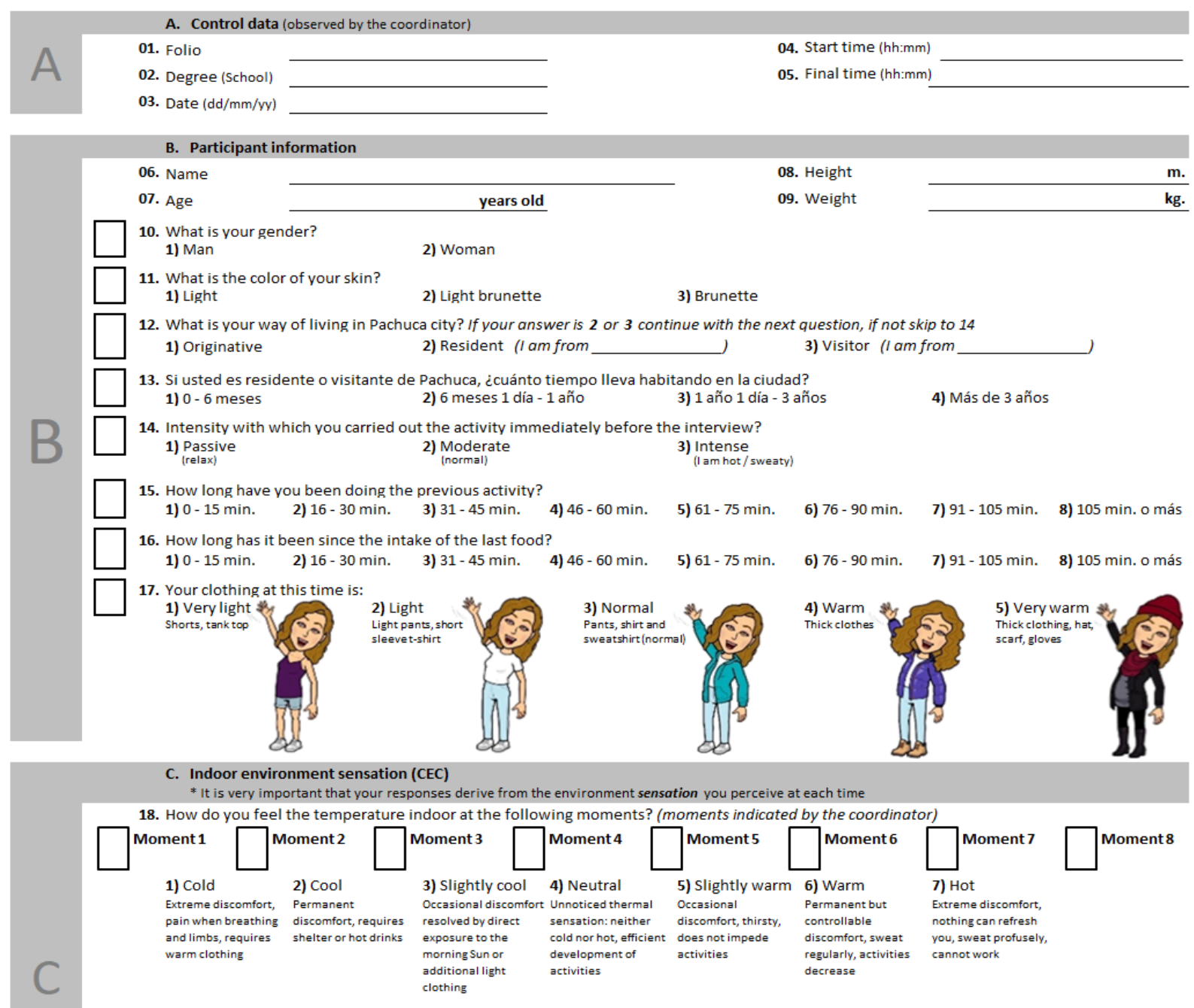

19. How do you feel the indoor relative humidity at the previous moments? (times indicated by the coordinator)

\begin{tabular}{|c|c|c|c|c|c|c|c|}
\hline Moment 1 & Moment 2 & Moment 3 & Moment 4 & Moment 5 & Moment 6 & Moment 7 & Moment 8 \\
\hline $\begin{array}{l}\text { 1) Very humid } \\
\text { Permanent } \\
\text { discomfort, } \\
\text { perspiration is } \\
\text { constant and wets } \\
\text { clothes }\end{array}$ & $\begin{array}{l}\text { 2) Humid } \\
\text { Mild moisture on the } \\
\text { skin, refreshing with } \\
\text { the circular wind }\end{array}$ & $\begin{array}{l}\text { 3) Slightly humid } \\
\text { Slight discomfort from } \\
\text { moisture but skin } \\
\text { remains dry }\end{array}$ & $\begin{array}{l}\text { 4) Neutral } \\
\text { Unnoticed sensation } \\
\text { of moisture: neither } \\
\text { dryness nor perceived } \\
\text { moisture }\end{array}$ & $\begin{array}{l}\text { 5) Slightly dry } \\
\text { Almost unnoticeable, } \\
\text { eventual dry lips }\end{array}$ & $\begin{array}{l}\text { 6) Dry } \\
\text { Occasional } \\
\text { discomfort, dry skin } \\
\text { and lips }\end{array}$ & $\begin{array}{l}\text { 7) Very dry } \\
\text { Permanent } \\
\text { discomfort, very dry } \\
\text { air, dry nose and } \\
\text { throat }\end{array}$ & \\
\hline
\end{tabular}

Front view 


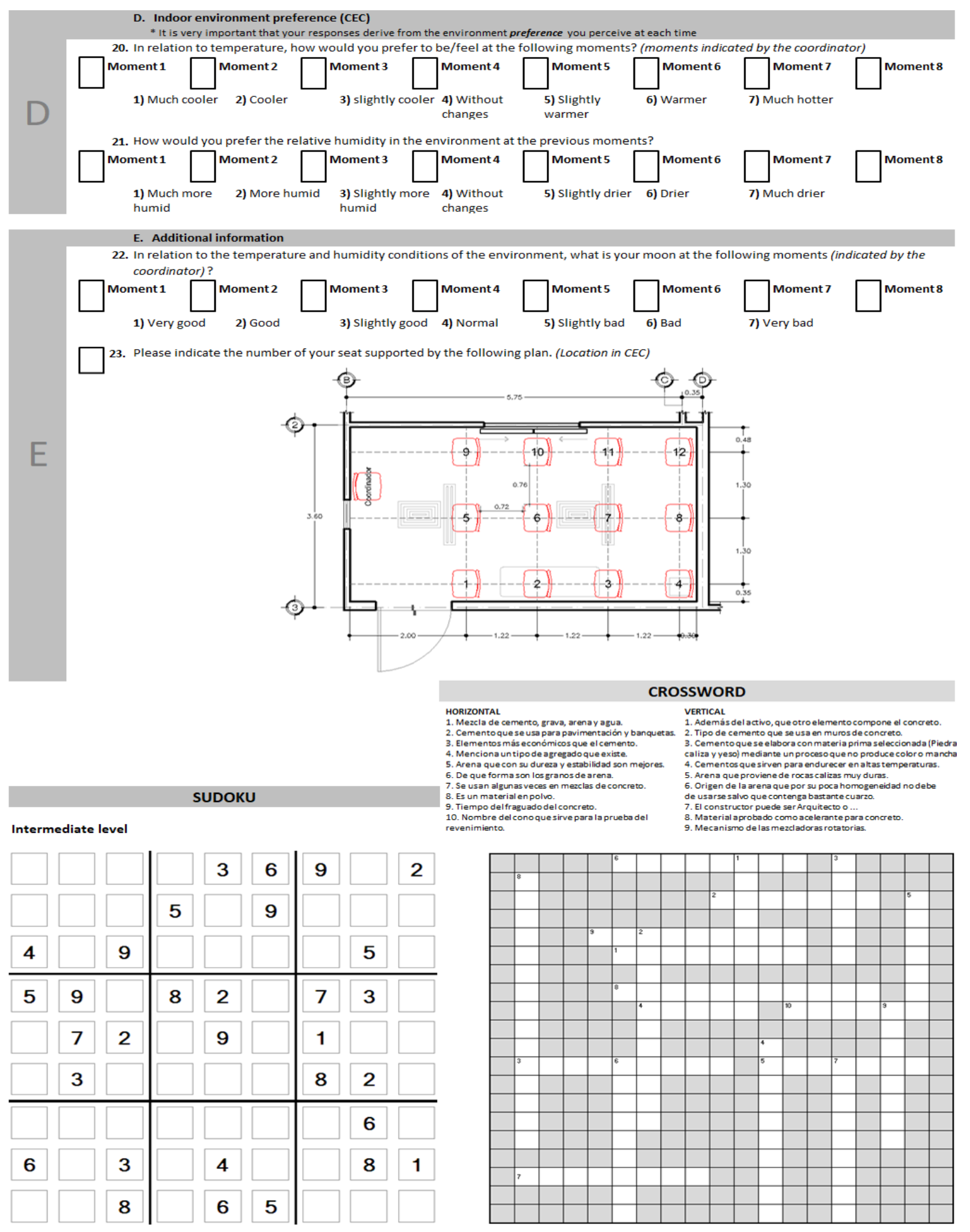

\section{Back view}




\section{REFERENCES}

[1] Auliciems A., S. Szokolay, "Thermal comfort," Notes Passive Low Energy Archit. Int., note 3, pp. 112-177, 1997. http://www.plea-arch.org/wp-content/uploads/PLEA-NOTE -3-THERMAL-COMFORT.pdf

[2] Olgyay V., Arquitectura y clima. Manual de diseño bioclimático para arquitectos y urbanistas, Gustavo Gili, 1963, pp. 1-216.

[3] TAREB. The low energy architecture research unit, London Metropolitan University, 2004.

[4] Brown R., T. Gillespie, Microclimatic landscape design, creating thermal comfort and energy efficiency, John Wiley \& Sons, 1995, pp.1-208.

[5] Critchfield H., General climatology, (3rd ed), Prentice-Hall, 1983, pp. 1-453.

[6] ISO 7730, Ergonomics of the thermal environment Analytical determination and interpretation of thermal comfort using calculation of the PMV and PPD indices and local thermal comfort criteria, International Organization for Standardization, Geneva, 2005.

[7] Auliciems A., Human bioclimatology (Advances in bioclimatology (5)), (1st ed.), Springer, 1998, pp. 1-196.

[8] Nikolopoulou M., Designing open space in the urban environment: A bioclimatic approach, (1st ed), Center for Renewable Energy Sources, 2004, pp. 1-52.

[9] ANSI/ASHRAE 55, Thermal environmental conditions for human occupancy, American Society of Heating, Refrigerating, and Air Conditioning Engineers, Atlanta, 2017.

[10] [10] Mishra A. K., M. Ramgopal, "A thermal comfort field study of naturally ventilated classrooms in Kharagpur, India," Building and Environment, vol. 92, pp. 396-406, 2015. DOI: 10.1016/j.buildenv.2015.05.024.

[11] Jindal A., "Thermal comfort study in naturally ventilated school classrooms in composite climate of India," Building and Environment, vol. 142, pp. 34-46, 2018. DOI: 10.1016/j.buildenv.2018.05.051.

[12] Buonocore C., De Vecchi R., Scalco V., R. Lamberts, "Thermal preference and comfort assessment in air-conditioned and naturally-ventilated university classrooms under hot and humid conditions in Brazil," Energy and Buildings, vol. 211, pp. 1-13, 2020. DOI: 10.1016/j.enbuild.2020.109783.

[13] Shandilya A., Hauer M., W. Streicher, "Optimization of thermal behavior and energy efficiency of a residential house using energy retrofitting in different climates," Civil Engineering and Architecture, vol. 8, no. 3, pp. 335-349, 2020. DOI: $10.13189 /$ cea.2020.080318.

[14] Wang Z., Zhang H., He Y., Luo M., Li Z., Hong T., B. Lin, "Revisiting individual and group differences in thermal comfort based on ASHRAE database," Energy and Buildings, vol. 219, pp. 1-14, 2020. DOI: 10.1016/j.enbuild.2020.110017.
[15] Ji W., Zhu Y., B. Cao, "Development of the predicted thermal sensation (PTS) model using the ASHRAE global thermal comfort database," Energy and Buildings, vol. 211, pp. 1-12, 2020. DOI: 10.1016/j.enbuild.2020.109780.

[16] Luo M., Xie J., Yan Y., Ke Z., Yu P., Wang Z., J. Zhanga, "Comparing machine learning algorithms in predicting thermal sensation using ASHRAE Comfort Database II," Energy and Buildings, vol. 210, pp. 1-16, 2020. DOI: 10.1016/j.enbuild.2020.109776.

[17] Montazami A., Gaterell M., Nicol F., Lumley M., C. Thouad, "Developing an algorithm to illustrate the likelihood of the dissatisfaction rate with relation to the indoor temperature in naturally ventilated classrooms," Building and Environment, vol. 111, pp. 61-71, 2017. DOI: 10.1016/j.buildenv.2016.10 .009 .

[18] Gómez-Azpeitia G., Gómez A., Elías P., R. Moreno, "Adaptación del índice humidex para el clima de la ciudad de Colima, México, de acuerdo con el Enfoque Adaptativo," in Rodríguez M. (comp.), Estudios de arquitectura bioclimática, (1st ed.), Limusa, 2006, 1-192.

[19] Nikolopoulou M., K. Steemers, "Thermal comfort and psychological adaptation as a guide for designing urban spaces," Energy and Building, vol. 35, pp. 95-101, 2003. DOI: 10.1016/S0378-7788(02)00084-1.

[20] Bojórquez G., Confort térmico en exteriores: Actividades en espacios recreativos, en clima cálido seco extremo, $\mathrm{PhD}$ Thesis, Universidad de Colima, México, 2010. https://sistemas.ucol.mx/tesis_posgrado/resumen1717.htm (accessed Jul 11, 2018).

[21] Humphreys M., F. Nicol, "Understanding the adaptive approach to thermal comfort," ASHRAE Transactions, vol. 104, pp. 991-1004, 1997.

[22] Critchfield H., General climatology, (4th ed), Pearson College Div, 1998, pp. 1-464.

[23] Bedford T., "The warmth factor in comfort at work: A physiological study of heating and ventilation," Report No. 76. HMSO, 1st ed., Industrial health research board, 1936.

[24] Fanger O., Thermal comfort, (1st ed.), McGraw-Hill, 1972, $1-244$.

[25] Nicol F., M. Humphreys, "Adaptive thermal comfort and sustainable thermal standards for buildings," Energy and Building, vol. 34, pp. 563-572, 2002. DOI: 10.1016/S0378-7788(02)00006-3.

[26] Brager G., R. de Dear, "Historical and cultural influences on comfort expectations," in Cole R. and R. Lorch (eds.), Buildings, culture and environment: Informing local and global practices, (1st ed), Blackwell, 2003, pp. 1-416.

[27] Yang Y., Li B., Liu H., Tan M., R. Yao, "A study of adaptive thermal comfort in a well-controlled climate chamber," Applied Thermal Engineering, vol. 76, pp. 283-291, 2015. DOI: 10.1016/j.applthermaleng.2014.11.004.

[28] Duan Q., J. Wang, "Thermal conditions controlled by thermostats: An occupational comfort and well-being perspective," Civil Engineering and Architecture, vol. 5, no. 5, pp. 173-179, 2017. DOI: 10.13189/cea.2017.050502.

[29] Liu S., Schiavon S., Prassana-Das H., Jin M., C. Spanos, "Personal thermal comfort models with wearable sensors," 
Building and Environment, vol. 162, pp. 1-17, 2019. DOI: 10.1016/j.buildenv.2019.106281.

[30] Loomans M.G.L.C., Mishra A.K., L. Kooi, "Long-term monitoring for indoor climate assessment-The association between objective and subjective data," Building and Environment, vol. 179, pp. 1-12, 2020. DOI: 10.1016/j.buildenv.2020.106978.

[31] Rincón J., Confort térmico en bioclima semi-frio: Estimación a partir de los enfoques de estudio adaptativo y predictivo (Caso de estudio: Centro de estudios de educación superior en Pachuca, Hidalgo), PhD Thesis, Universidad Autónoma Metropolitana, México, 2015. https://uabc.academia.edu/JulioRincon/Thesis-Chapters (accessed Feb 12, 2018).

[32] de Dear R., Brager G., D. Cooper, "Developing an adaptive model of thermal comfort and preference (final report on RP-884)," ASHRAE and Macquarie Research Ltd, USA, 1997.

[33] Van-Craenendonck S., Lauriks L., J. Kampen, “A review of human thermal comfort experiments in controlled and semi-controlled environments," Renewable and Sustainable Energy Reviews, vol. 82, no. 3, pp. 3365-3378, 2018. DOI: 10.1016/j.rser.2017.10.053.

[34] Fanger O., Thermal comfort: Analysis and applications in environmental engineering, (1st ed.), McGraw-Hill, 1970, pp. 1-244.

[35] Bravo G., E. González, "Confort térmico en el trópico: Hacia un estándar en viviendas naturalmente ventiladas," Información tecnológica, vol. 12, no. 5, pp. 169-174, 2001. https://books.google.com.mx/books?id=WPLrWlW7CJAC \&pg=PP2 (accessed Jan 34, 2018).

[36] ISO 8996, Ergonomics of the thermal environment Determination of metabolic rate, International Organization for Standardization, Geneva, 2004.

[37] ISO 7726, Ergonomics of the thermal environment-Instruments for measuring physical quantities, International Organization for Standardization, Geneva, 1998.

[38] Christensen L. Experimental methodology, (10th ed), Allyn \& Bacon, 2006, pp. 1-544

[39] Bernal J., "Elaboración de la metodología de seguimientos de la instrumentación del laboratorio de ambiente controlado (LAC)," in FI-Posgrado (ed.), Informe de seminario de proyectos I y II, Universidad Autónoma Metropolitana (Iztapalapa), 2007, pp. 1-276.

[40] Nicol F., Thermal comfort: A handbook for field studies toward an adaptive model, (1st ed.), University of East London, 1993, pp. 1-85.

[41] Hernández R., Fernández C., P. Baptista, Metodología de la investigación, (6th ed.), McGraw-Hill, 2018, pp. 1-715.

[42] Gómez-Azpeitia G., et al., Monitoreo de condiciones de confort térmico: Reporte técnico (Producto 3), CONAFOVI 2004-01-20, 2007.

[43] Fernández L., “¿Cómo se elabora un cuestionario?,” in Universitat de Barcelona (ed.), Butlleti LaRecerca, (1st ed.), Institut de Ciencies de l'Educacio, 2007, pp. 1-65.

[44] Namakforoosh M., Metodología de la investigación, (2nd ed), Limusa, 2000, pp. 1-528.

[45] Carrera F., J. Ambríz, Evaluación experimental de las condiciones de confort higrotérmico en un grupo representativo de la población mexicana, Undergraduate thesis, Universidad Autónoma Metropolitana, México, 2008 .

[46] Innova, Thermal comfort (Booklet), (1st ed), Author, 2002. 